\title{
Small peptide inhibitor of JNKs protects against MPTP-induced nigral dopaminergic injury via inhibiting the JNK-signaling pathway
}

\author{
Jing Pan ${ }^{1,2}$, Jing Qian ${ }^{1}$, Yu Zhang ${ }^{1,2}$, Jianfang Ma², Gang Wang ${ }^{2}$, Qin Xiao², Shengdi Chen ${ }^{1,2}$ and Jianqing Ding ${ }^{1,2}$
}

Increasing evidence suggests that apoptosis may be the mechanism underlying cell death in selective loss of nigral dopaminergic neurons in Parkinson's disease (PD). Previous studies strongly suggested that c-Jun N-terminal kinase (JNK) signaling pathway has a critical role in the animal model with 1-methyl-4-phenyl-1,2,3,6-tetrahydropyridine (MPTP)induced PD. In this study, we report the inhibitory effect of a peptide designated as Tat-JBD on JNKs activation. The sequence of Tat is corresponding to the cell-membrane transduction domain of human immunodeficiency virus-type 1 (HIV-1) and the sequence of an 11-amino acid peptide is corresponding to the residues of JNK-binding domain (JBD) on JNK-interacting protein-1 (JIP-1). Tat-JBD is confirmed to perturb the assembly of JIP-1-JNKs complex, inhibit the activation of JNKs induced by MPTP and consequently diminish the phosphorylation of c-Jun. It also inhibits the phosphorylation of $\mathrm{Bcl}-2$ and the releasing of Bax from Bcl-2/Bax dimmers, sequentially attenuates the translocation of Bax to mitochondria, the release of cytochrome $c$, the activation of caspase 3 and the hydrolyzation of poly-ADP-ribosepolymerase. The death of dopaminergic neurons and the loss of dopaminergic axon in the striatum were significantly suppressed by infusion of the peptide Tat-JBD in MPTP-treated mice. Our findings imply that Tat-JBD offers neuroprotection against MPTP injury via inhibiting the JNK-signaling pathway, and may provide a promising therapeutic approach for PD.

Laboratory Investigation (2010) 90, 156-167; doi:10.1038/labinvest.2009.124; published online 14 December 2009

KEYWORDS: JNKs; Tat-JBD; JIP-1; neuronal death; dopaminergic neuron

Parkinson's disease (PD) is a common neurodegenerative disorder in which apoptosis maybe the main cause for selective loss of dopamine-containing neurons in the midbrain. ${ }^{1}$ Undoubtedly, effective treatments for PD depend largely on our understanding of the molecular mechanisms of the disease, which is still incomplete. Yet, significant hints into the pathogenesis of PD have been yielded by the use of 1-methyl-4-phenyl-1,2,3,6-tetrahydropyridine (MPTP), a neurotoxin that replicates most of the neuropathological hallmarks of PD in humans. ${ }^{2,3}$ Although the MPTP mouse model departs from human PD in a few ways, it still offers a unique means to investigate molecular events underlying the demise of midbrain dopaminergic neurons in vivo. ${ }^{2,3}$ Mitogen-activated protein kinases (MAPK) have a critical role in promoting survival or inducing cell death. c-Jun $\mathrm{N}$-terminal kinase (JNK), a member of MAPK family, is activated by a variety of stimuli including neurotoxic insults, environmental stress and apoptotic agents. ${ }^{4-6}$ Activated JNK in turn phosphorylates its substrates including c-Jun, ATF-2, ELK1 and p53, leading to excitotoxicity and neuronal death. ${ }^{4,7} \mathrm{JNKs}$ consist of JNK1, JNK2 and JNK3, in which JNK3 is largely restricted to the brain within neurons, whereas JNK1 and JNK2 are ubiquitously expressed. ${ }^{8,9}$ Examination of various JNK-deficient mice shows that both JNK2 and JNK3 are required for MPTP-induced c-Jun activation and dopaminergic cell demise. ${ }^{10}$ JNK3 knock-out provides long-lasting protection against axotomy and it is at least transiently protective against 6-hydroxydopamine (6-OHDA). ${ }^{11}$ This suggested that JNKs especially JNK3 may have an important role in mediating neuronal apoptosis and blockade of JNKs by specific inhibitors may prevent or effectively slow down the progression of $\mathrm{PD} .^{8,9}$

${ }^{1}$ Institute of Health Science, Shanghai Institutes for Biological Sciences (SIBS), Chinese Academy of Sciences (CAS) \& Shanghai Jiao Tong University School of Medicine, Shanghai, PR China and 2Department of Neurology and Institute of Neurology, Ruijin Hospital, Shanghai Jiao Tong University School of Medicine, Shanghai, PR China Correspondence: Dr SD Chen, MD or Dr JQ Ding, MD, Department of Neurology and Institute of Neurology, Jiao-Tong University School of Medicine, Ruijin Hospital, Shanghai, 197 Ruijin 2nd Road, Shanghai 200025, PR China.

E-mail: chen_sd@medmail.com.cn or jqding18@yahoo.com

Received 18 April 2009; revised 1 October 2009; accepted 6 October 2009 
Previous studies have suggested that JNK-interacting protein-1 (JIP-1), one member of JNK scaffolds family, is a key factor for JNK activation. It functions as a scaffold protein and carries JNK, MKK7 and MLK3 to form MAPK cascade. The cascade formation is critical for JNK activation. ${ }^{12,13}$ The JNK-binding domain of JIP-1 (JBD) is located at residues 127-282, the $\mathrm{N}$ terminus of the protein. ${ }^{14}$ Eilers's ${ }^{15}$ results showed overexpression of JBD can inhibit JNK activation and reduce the apoptosis induced by the withdrawal of nerve growth factor in PC12 cells. Apoptosis was also reduced or prevented by overexpression of the JBD in the insulin-secreting cells or sympathetic neurons. ${ }^{16-18}$ The overexpressed JBD appears to effectively inhibit the JNK pathway by disrupting the scaffolded JNK upstream components. ${ }^{19}$ Barr $^{20}$ further reported a 11-amino acid JIP-1-derived (residues 153-163 of JIP-1) peptide can also effectively inhibit interleukin-1-induced c-jun expression and protect against interleukin-1-induced pancreatic cell apoptosis. On the basis of the above results, we synthesized the 11-mer peptide (Arg-Pro-Lys-Arg-Pro-Thr-Thr-Leu-AsnLeu-Phe) mentioned in Barr et al ${ }^{20}$ paper and fused it with Tat peptide (Tyr-Gly-Arg-Lys-Lys-Arg-Arg-Gln-Arg-ArgArg) originated from the cell-membrane transduction domain of HIV-1 to obtain a 22 -amino acid fusion peptide, Tat-JBD. The peptide was evaluated in vitro to ascertain its feature as a JNK inhibitor. An in vivo study showed that this peptide alone was sufficient to inhibit the activation of JNKs in MPTP-treated mice. Furthermore, we showed that this peptide could decrease MPTP-induced injuries to dopaminergic cell bodies and terminals via inhibiting both nuclear and non-nuclear pathways of JNKs.

\section{MATERIALS AND METHODS Animals}

Studies were conducted in male C57BL/6 mice (8-10 weeks old, weighing 19-22 g). Five animals were housed, per cage, in a temperature-controlled $\left(25^{\circ} \mathrm{C}\right)$ room under a $12: 12-\mathrm{h}$ light/dark cycle with ad libitum access to food and water for 1 week before the experiment. The mice were injected intraperitoneally (i.p.) five times (for 5 consecutive days) with $30 \mathrm{mg} / \mathrm{kg} /$ day MPTP-HCl (Sigma, St Louis, MO, USA) or a corresponding volume of saline alone. At the indicated time points, the animals were killed, and their brains were processed for further analysis.

\section{Materials}

Mouse monoclonal anti-p-JNKs (sc-6254), mouse monoclonal anti-p-c-Jun (sc-822), rabbit polyclonal anti-Fas L (sc-6237), rabbit polyclonal anti-p-Bcl-2 (Ser87), rabbit polyclonal anti-Fas (sc-716), rabbit polyclonal anti-c-Jun (sc1694), rabbit polyclonal anti-JIP-1 (sc-15353), rabbit polyclonal anti-actin (sc-10731) and rabbit polyclonal anti-PARP (sc-7150) were purchased from Santa Cruz Biotechnology (Santa Cruz, CA, USA). Rabbit polyclonal anti-Bax (no. 2772), rabbit polyclonal anti-Cytochrome $c$ (no. 4272), rabbit polyclonal anti-cleaved Caspase3 (no. 9661) and rabbit polyclonal anti-Caspase3 (no. 9660) was obtained from Cell Signal Biotechnology (Cell Signaling Technology, Danvers, MA, USA). Rabbit polyclonal anti-JNK3 antibody (06-749) was obtained from Upstate Biotechnology (Dundee, UK). The secondary antibodies used in our experiment were goat anti-mouse IgG and goat anti-rabbit IgG. They were from Sigma-Aldrich China (Shanghai, China). ApopTag Peroxidase In situ Apoptosis Detection Kit (S7100) was purchased from Chemicon International (Temecula, CA, USA).

\section{Cloning of JNK3, JNK2 and GST-JIP1 (127-282)}

JNK3 (Ser40-Gln422), JNK2 (full legnth) and JIP1(127-282) cDNA were obtained through RT-PCR, then were inserted into vectors pET-28a (Novagen) and pGEX-5X-1 (Amersham-Pharmacia Biotech), respectively. Owing to the poor solubility of full-length JNK3 (Met1-Gln422) (data not shown), we constructed a vector, which expressed JNK3 (Ser40-Gln422) (JNK3 $\alpha 1)$ truncated protein (Ser40-Gln422) as described in Xie et al. ${ }^{21}$

\section{Expression and Purification of Truncated JNK3 and GST-JIP1 (127-282)}

Escherichia coli. strain BL21(DE3) (Novagen) transformed with the truncated JNK3 (Ser40-Gln422), JNK2 (full length) and GST-JIP1 (127-282) expression construct were grown at $37^{\circ} \mathrm{C}$ in shaker flasks in Luria broth. At A600 $=0.4$ culture was induced with $0.1 \mathrm{mM}$ (final concentration) of isoproplthion- $\beta$-D-galactoside (IPTG, Sigma) and grown with shaking at $18^{\circ} \mathrm{C}$ overnight and harvested at $4^{\circ} \mathrm{C}$ by centrifugation.

Cell pellets from a $100 \mathrm{ml}$ culture were resuspended in $5 \mathrm{ml}$ lysis buffer $\left(50 \mathrm{mM} \mathrm{NaH}_{2} \mathrm{PO}_{4}, \mathrm{pH} 7.5,300 \mathrm{mM} \mathrm{NaCl}, 10 \mathrm{mM}\right.$ imidazole, $1 \mathrm{mM}$ PMSF) and were then sonicated $6 \times 10 \mathrm{~s}$ with $10 \mathrm{~s}$ pauses at $200-300 \mathrm{~W}$. Lysates were centrifuged at 4000 r.p.m. at $4^{\circ} \mathrm{C}$ for $30 \mathrm{~min}$. The supernatants obtained from centrifugation were mixed with Ni-NTA agarose (Qiagen) or glutathione agarose (GE-Healthcare) and then incubated with shaking at $4^{\circ} \mathrm{C}$ for $60 \mathrm{~min}$. After loading the mixture into an empty column, the matrix was washed with wash buffer and the truncated JNK3, full length of JNK2 or GST-JIP1 (127-282) protein was eluted with elution buffer. Protein fractions were analyzed by SDS-PAGE and Coomassie brilliant blue staining.

\section{GST Pull-Down Assays}

To assess the inhibitory function of Tat-JBD toward JNK $3 \alpha 1$ or JNK2, we performed pull-down assays. Initially, JNK3 $\alpha 1$ or JNK2 was preincubated with peptide of Tat-JBD (ArgPro-Lys-Arg-Pro-Thr-Thr-Leu-Asn-Leu-Phe-Tyr-Gly-ArgLys-Lys-Arg-Arg-Gln-Arg-Arg-Arg) or Tat-JBD-4A, a mutated Tat-JBD peptide in which the DNA sequence of its $\mathrm{N}$-terminal motif contains four-point mutations (Arg-ProLys-Ala-Ala-Thr-Thr-Ala-Asn-Ala-Phe-Tyr-Gly-Arg-LysLys-Arg-Arg-Gln-Arg-Arg-Arg), at RT for $90 \mathrm{~min}$. Later, 
GST-JIP1 (127-282) fusion proteins bound to glutathione agarose beads were incubated with JNK3 $\alpha 1+$ Tat-JBD, JNK $3 \alpha 1+$ Tat-JBD-4A, JNK2 + Tat-JBD and JNK2 + TatJBD-4A at RT for $2 \mathrm{~h}$, respectively. The beads were washed by $1 \times$ PBS buffer and eluted with elution buffer $(50 \mathrm{mM}$ Tris$\mathrm{HCl}, 10 \mathrm{mM}$-reduced glutathione, $\mathrm{pH}$ 7.5). Proteins were analyzed by SDS-PAGE and Coomassie blue R250 staining.

\section{Drug Treatment}

Peptide Tat-JBD $(100 \mu \mathrm{g})$ or control peptide $(100 \mu \mathrm{g})$ was dissolved in $4 \mu \mathrm{l} 0.9 \%$ saline. Drug infusions were performed using a microinjector through cerebral ventricles (from the bregma: anteroposterior, $-0.8 \mathrm{~mm}$; lateral, $1.2 \mathrm{~mm}$; depth, $2.8 \mathrm{~mm}$ ). Four microliter of each peptide was infused over $5 \mathrm{~min}$. Tat-JBD or Tat-JBD-4A were given once per day for 5 consecutive days in a successful PD model and infusion of $0.9 \%$ saline served as a vehicle control.

\section{Tissue Preparation}

Mice were killed on day 11 under anesthesia, and then substantia nigra pars compacta (SNc) and striatal tissue were isolated and immediately frozen in liquid nitrogen. The SNc and striatum were homogenized in ice-cold homogenization buffer (buffer A) containing $50 \mathrm{mM}$ 3-( $N$-morpholino) propanesulfonic acid (Sigma; pH 7.4), $100 \mathrm{mM} \mathrm{KCl}, 320 \mathrm{mM}$ sucrose, $50 \mathrm{mM} \mathrm{NaF}, 0.5 \mathrm{mM} \mathrm{MgCl} 2,0.2 \mathrm{mM}$ dithiothreitol, $1 \mathrm{mM}$ ethylenediamine tetra acetic acid (EDTA), $1 \mathrm{mM}$

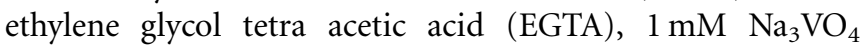
(Sigma), $20 \mathrm{mM}$ sodium pyrophosphate, $20 \mathrm{mM} \beta$-phosphoglycerol, $1 \mathrm{mM}$ p-nitrophenyl phosphate, $1 \mathrm{mM}$ benzamidine, $1 \mathrm{mM}$ phenylmethylsulfonyl fluoride (PMSF), and $5 \mathrm{mg} / \mathrm{ml}$ each of leupeptin, aprotinin and pepstatin A. The homogenates were centrifuged at $1000 \mathrm{~g}$ for $10 \mathrm{~min}$ at $4^{\circ} \mathrm{C}$. Cytosolic fractions in the supernatants were collected, and protein concentrations were determined. The samples were stored at $-80^{\circ} \mathrm{C}$ until further use. These were performed as per the protocol of our previous study. ${ }^{22-25}$

\section{Crude Mitochondrial Fraction Extraction}

Tissue samples for western blot analysis of cytochrome $c$ (cyt $c$ ) were immediately isolated to prepare subcellular fractions. All procedures were conducted in a cold room. Non-frozen brain tissue was used to prepare mitochondrial fractions because freezing tissue causes release of cyt $c$ from mitochondria. The tissue samples were homogenized in 1:10 $(\mathrm{w} / \mathrm{v})$ cold homogenization buffer $\mathrm{A}$. The homogenates were centrifuged at $1000 \mathrm{~g}$ for $10 \mathrm{~min}$ at $4^{\circ} \mathrm{C}$. The pellets were discarded and supernatants were further centrifuged at $17000 \mathrm{~g}$ for $20 \mathrm{~min}$ at $4^{\circ} \mathrm{C}$ to yield the cytosolic fraction in the supernatants and the crude mitochondrial fraction in the pellets. ${ }^{22}$

\section{Nuclear Extraction}

Tissue homogenates were centrifuged at $1000 \mathrm{~g}$ for $10 \mathrm{~min}$, the pellets were extracted with $20 \mathrm{mM} \mathrm{4-(2-hydroxyethyl)-1-}$ piperazineethanesulfonic acid (HEPES), $\mathrm{pH} 7.9,20 \%$ glycerol, $420 \mathrm{mM} \mathrm{NaCl}, 0.5 \mathrm{mM} \mathrm{MgCl} 2,1 \mathrm{mM}$ EDTA, $1 \mathrm{mM}$ EGTA, $1 \mathrm{mM}$ DTT and enzyme inhibitors for $30 \mathrm{~min}$ at $4^{\circ} \mathrm{C}$ with constant agitation. After centrifugation at $12000 \mathrm{~g}$ for $15 \mathrm{~min}$ at $4^{\circ} \mathrm{C}$, the nuclear fraction in the supernatants was collected, and the protein concentrations were determined. The samples were stored at $-80^{\circ} \mathrm{C}$ and were thawed only once. $^{22-25}$

\section{Immunoprecipitation and Immunoblotting}

Tissue homogenates ( $400 \mu \mathrm{g}$ of protein) were diluted fourfold with $50 \mathrm{mM}$ HEPES buffer ( $\mathrm{pH} 7.4$ ), containing $10 \%$ glycerol, $150 \mathrm{mM} \mathrm{NaCl}, 1 \%$ Triton X-100, $0.5 \%$ NP-40, and $1 \mathrm{mM}$ each of EDTA, EGTA, PMSF and $\mathrm{Na}_{3} \mathrm{VO}_{4}$. Samples were preincubated for $1 \mathrm{~h}$ with $20 \mu \mathrm{l}$ protein A sepharose CL-4B (Amersham, Uppsala, Sweden) at $4{ }^{\circ} \mathrm{C}$, and then centrifuged to remove proteins adhered non-specifically to protein A. The supernatants were incubated with 1-2 $\mu$ g primary antibodies for $4 \mathrm{~h}$ or overnight at $4^{\circ} \mathrm{C}$. Protein $\mathrm{A}$ was added to the tube for another 2-h incubation. Samples were centrifuged at $10000 \mathrm{~g}$ for $2 \mathrm{~min}$ at $4^{\circ} \mathrm{C}$ and the pellets were washed with HEPES buffer three times. Bound proteins were eluted by boiling at $100^{\circ} \mathrm{C}$ for $5 \mathrm{~min}$ in SDS-PAGE loading buffer and then isolated by centrifugation. The supernatants were used for immunoblotting analysis. Proteins were separated on polyacrylamide gels and then electrotransferred onto a nitrocellulose membrane (Amersham, Buckinghamshire, UK). After being blocked for $3 \mathrm{~h}$ in Tris-buffered saline with $0.1 \%$ Tween 20 (TBST) and $3 \%$ bovine serum albumin (BSA), membranes were incubated overnight at $4^{\circ} \mathrm{C}$ with primary antibodies in TBST containing 3\% BSA. After washing for $30 \mathrm{~min}$ in TBS with gentle agitation, the membrane was incubated with horseradish peroxidase-conjugated anti-mouse/rabbit IgG secondary antibody at room temperature for $2 \mathrm{~h}$. Signals were developed using ECL western blotting detection kit (Amersham-Pharmacia Biotech, Little Chalfont, UK). Band intensities were quantified by densitometric analyses using an AxioCam digital camera (ZEISS, CTED PROOF Germany) and a KS400 photo analysis system (Version 3.0).

\section{Histological Assessment and Immunohistochemistry}

Mice were perfusion-xed on day 11 with $4 \%$ paraformaldehyde in $0.1 \mathrm{M}$ sodium phosphate buffer ( $\mathrm{pH}$ 7.4). Brains were removed quickly and further xed with the same xation solution at $4^{\circ} \mathrm{C}$ overnight. Post-xed brains were embedded by paraffin, followed by preparation of coronal sections using a microtome. The paraffin-embedded brain sections were deparaffinized with xylene and rehydrated by ethanol at graded concentrations of $100-70 \% \quad(\mathrm{v} / \mathrm{v})$, followed by washing with water.

Immunoreactivity was determined by the avidin-biotinperoxidase method. Briefly, sections were deparaffinized with xylene and rehydrated by ethanol at graded concentrations and distilled water. High-temperature antigen retrieval was 
performed in $1 \mathrm{mM}$ citrate buffer for $15 \mathrm{~min}$. To block endogenous peroxidase activity, sections were incubated for $30 \mathrm{~min}$ in $1 \% \mathrm{H}_{2} \mathrm{O}_{2}$. After being blocked with $5 \%(\mathrm{v} / \mathrm{v})$ normal goat serum in PBS for $1 \mathrm{~h}$ at $37^{\circ} \mathrm{C}$, sections were incubated with a mouse polyclonal antibody against tyrosine hydroxylase ( $\mathrm{TH}, 1: 8000)$ at $4{ }^{\circ} \mathrm{C}$ for $24 \mathrm{~h}$. These sections were then incubated with biotinylated goat-anti-mouse secondary antibody overnight and subsequently with avidin-conjugated horseradish peroxidase for $1 \mathrm{~h}$ at $37^{\circ} \mathrm{C}$. Finally, sections were incubated with peroxidase substrate diaminobenzidine until the desired stain intensity developed.

TUNEL staining was performed using an ApopTag Peroxidase in situ apoptosis detection kit according to the manufacturer's protocol with minor modifications. The paraffin-embedded coronal sections were deparaffinized and rehydrated, and then treated with protease $\mathrm{K}$ at $20 \mu \mathrm{g} / \mathrm{ml}$ for $15 \mathrm{~min}$ at room temperature. Sections were incubated with the reaction buffer containing $\mathrm{TdT}$ enzyme and at $37^{\circ} \mathrm{C}$ for $1 \mathrm{~h}$. After washing with stop/wash buffer, sections were treated with anti-digoxigenin conjugate for $30 \mathrm{~min}$ at room temperature and subsequently developed color in peroxidase substrate. The nuclei were lightly counterstained with $0.5 \%$ Methyl Green.

\section{TH-Positive Cell and TUNEL-Positive Cell Counting}

To confirm the protection effect of Tat-JBD, the total number of dopaminergic neurons in the SNc was counted through the method of Furuya $e t a l^{26}$ in four mice per group. In brief, immunohistochemistry was performed as described above in $20-\mu \mathrm{m}$ thick nigral coronal sections. TH-positive neurons were counted in the right and left SNc of every fourth section throughout the entire extent of the SNc. The number of TH-positive cells were counted manually with 'Image Tool' of UTHSCSA (The University of Texas Health Science Center a

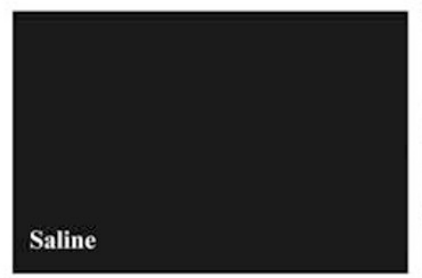

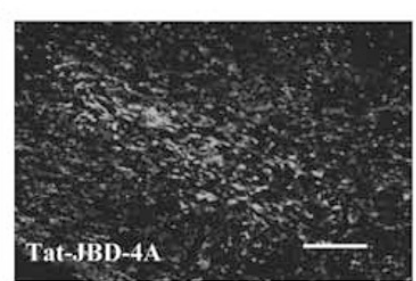

b

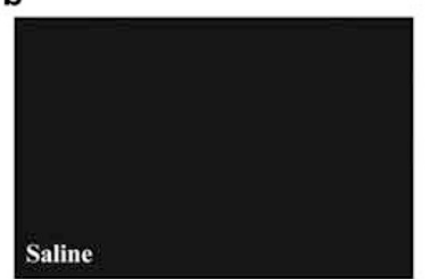

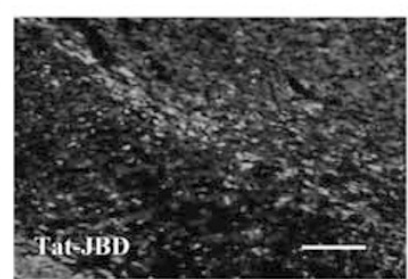

MPTP
C

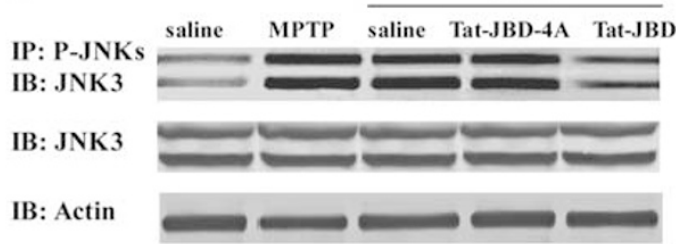

e

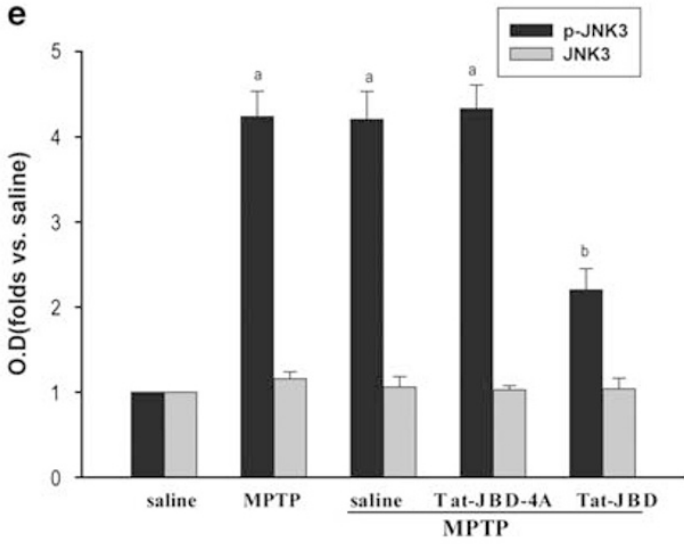

d

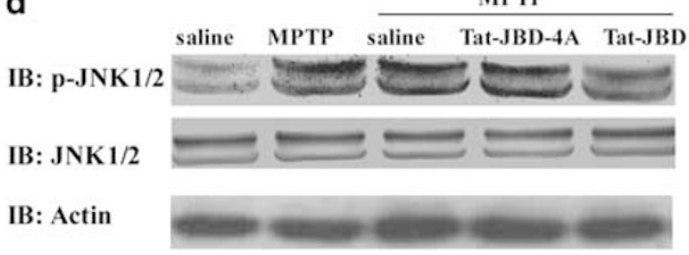

f

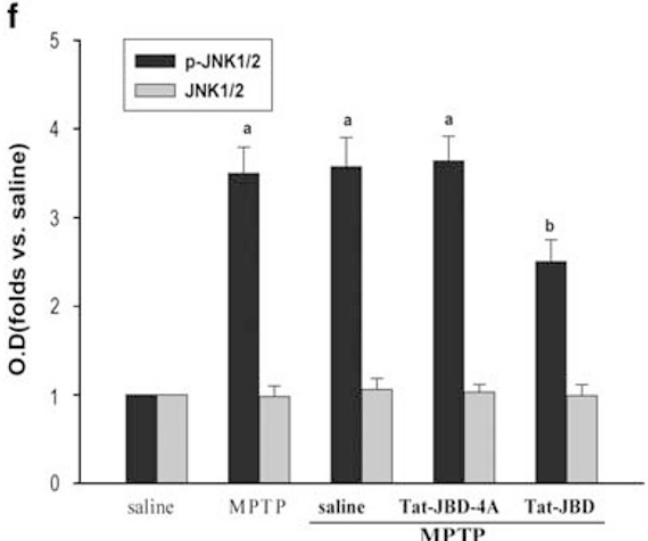

Figure 1 Effects of Tat peptides on the phosphorylation of JNK3 and JNK1/2. (a and b) Fluorescence can be observed in SNc of mice subjected cerebral ventricular injection of Tat-JBD-dansyl and Tat-JBD-4A-dansyl, whereas the same region showed only background signal in the mice treated with saline. a and b: $\times 40$; scale bar in $\mathbf{d}=200 \mu \mathrm{m}$. (c and e) Effects of Tat peptides on the phosphorylation of JNK3 in SNc. Bands corresponding to JNK3 and p-JNK3 were scanned and the intensities were represented as folds vs saline animals. (d and f) Effects of Tat peptides on the phosphorylation of JNK1/2 in SNc fraction. Bands corresponding to JNK1/2 and p-JNK1/2 were scanned and the intensities were represented as folds vs saline groups. Phosphorylation of JNK3 was examined by immunoprecipitation (IP) with anti-p-JNKs antibody followed by immunoblotting (IB) with the antibody against JNK3. Phosphorylation of JNK1/2 was examined by IB with anti-p-JNK1/2. The protein levels of JNK3 and JNK1/2 were examined by immunoblotting with anti-JNK3 and anti-JNK1/2 antibodies. Data are expressed as the mean \pm s.d. and as folds vs respective saline groups. ${ }^{a} P<0.05$ vs saline; ${ }^{b} P<0.05$ vs MPTP groups ( $n=6$ mice). 
at San Antonio) by researchers blinded to the treatment schedule. ${ }^{27}$ Four coronal sections (one of every two sections) of the middle part of substantia nigra from each animal were used for TUNEL staining with apoptosis detection kit of Chemicon International. The number of TUNEL-positive cells within the anatomical boundaries of $\mathrm{SNc}$ were counted with the aid of 'Image Tool' too. ${ }^{28}$ The total number of TH-positive and TUNEL-positive cells in different groups of mice were compared.

\section{Statistical Evaluation}

Values were expressed as mean s.d. and obtained from at least six independent experiments. Statistical analysis of the results was carried out by Student's $t$-test or one-way analysis of the variance followed by the Duncan's new multiple range method or Newman-Keuls test. $P$-values $<0.05$ were considered significant.

\section{RESULTS}

\section{Tat-JBD Suppresses JNK Activation}

To disrupt the interaction between JIP-1 and JNK, we constructed a peptide comprising residues 153-163 of murine JIP-1, which was conserved in sapiens and rodents. Tat peptide, which was obtained originally from the cell-membrane transduction domain of the human immunodeficiency virus-type 1 (HIV-1), was fused to JBD and resulted in a 22-amino acid fusion peptide, Tat-JBD.

We first examined the distribution of the peptides in the brain of the mouse. The fluorophore dansyl chloride was conjugated to Tat-JBD and Tat-JBD-4A, respectively.

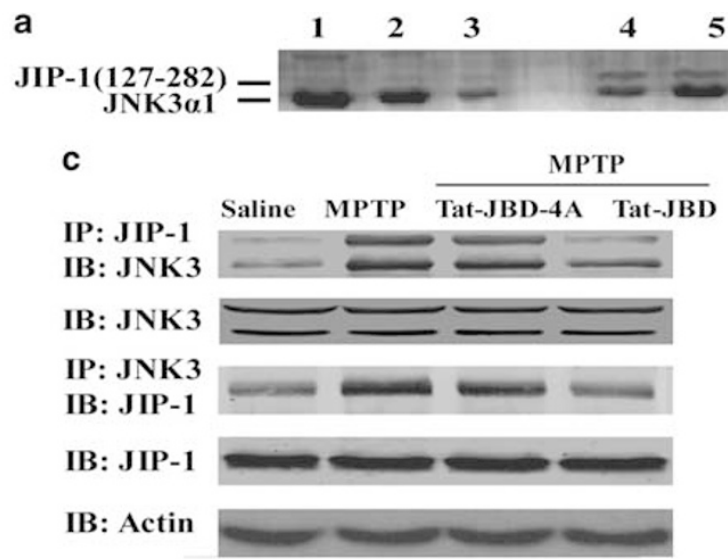

6

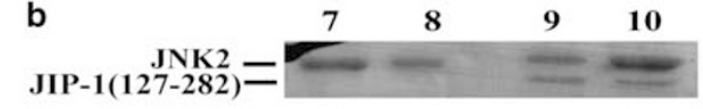

d
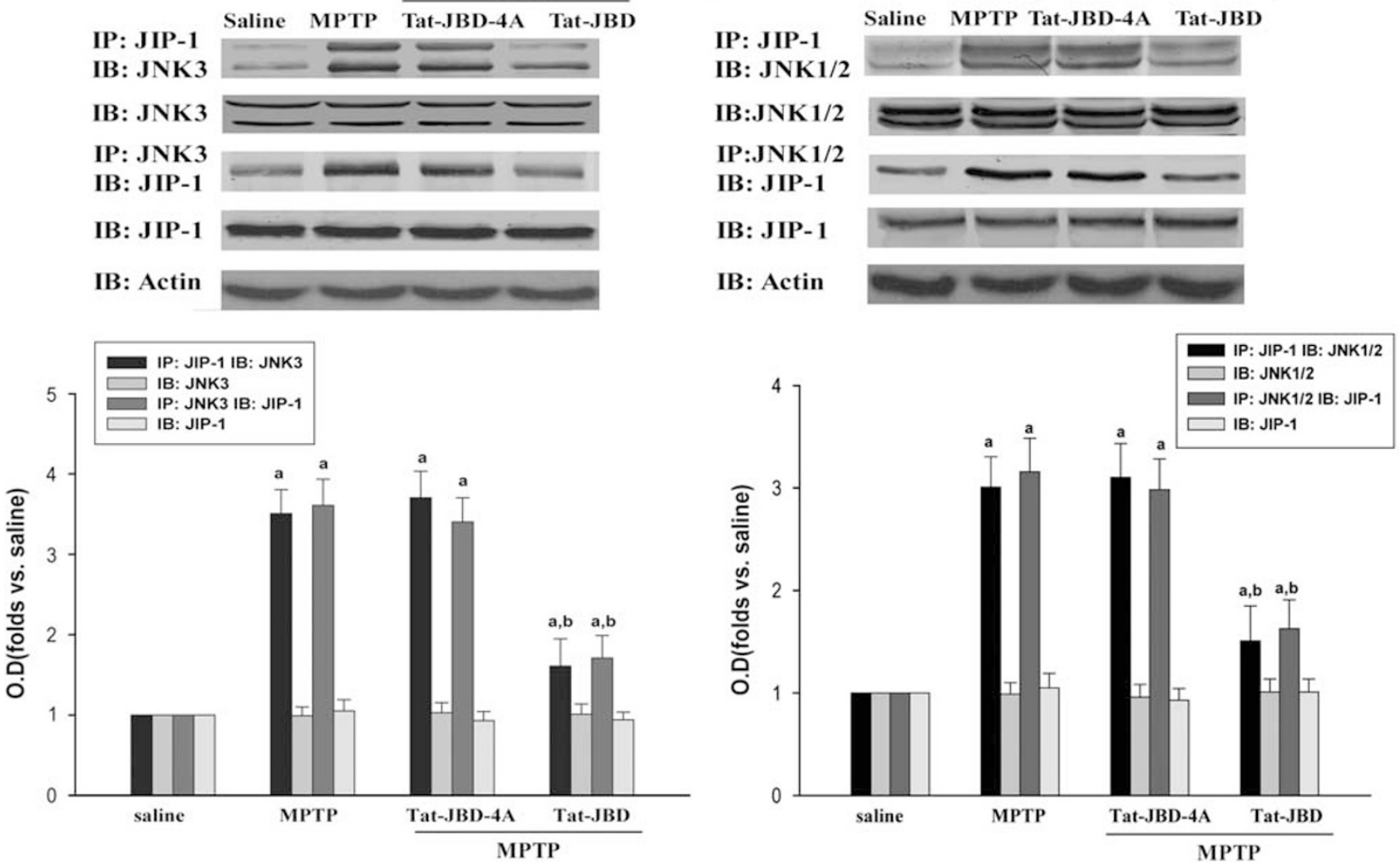

Figure 2 Tat-JBD could inhibit JP-1-JNK3 interaction in vitro and in vivo. Dissociating effects of Tat peptides on the JIP-1-JNK3 interaction. (a and $\mathbf{b}$ ) His-JNK3(40-422), His-JNK2(full length) and GST-JIP1(127-282) were expressed and purified. Purified JNK3 $\alpha 1$ was preincubated with $10 \mu \mathrm{M}$ Tat-JBD-4A (final concentration), $10 \mu \mathrm{M}$ or $20 \mu \mathrm{M}$ of Tat-JBD (final concentration), whereas JNK2 was preincubated with $10 \mu \mathrm{M}$ Tat-JBD-4A and $10 \mu \mathrm{M}$ Tat-JBD (final concentration), respectively. GST-JIP1(127-282) fusion proteins bound to glutathione agarose beads were incubated with above mixtures and eluted with elution buffer. Proteins were analyzed by SDS-PAGE and Coomassie blue R250 staining. Lane 1-3 and 7-8: flow-through, Lane 4-6 and 9-10: elution. 1, JNK3 $\alpha 1+20 \mu \mathrm{M}$ Tat-JBD 2, JNK3 $\alpha 1+10 \mu \mathrm{M}$ Tat-JBD 3, JNK3 $\alpha 1+10 \mu \mathrm{M}$ Tat-JBD-4A 4, JNK3 $\alpha 1+20 \mu \mathrm{M}$ Tat-JBD 5, JNK3 $\alpha 1+10 \mu \mathrm{M}$ Tat-JBD 6, JNK3 $\alpha 1+10 \mu \mathrm{M}$ Tat-JBD-4A. 7, JNK2 + $10 \mu \mathrm{M}$ Tat-JBD 8, JNK2 + $10 \mu \mathrm{M}$ Tat-JBD-4A 9, JNK2 + $10 \mu \mathrm{M}$ Tat-JBD 10, JNK2 + $10 \mu \mathrm{M}$ Tat-JBD-4A. (c and d) Co-immunoprecipitation of JIP-1 with JNKs subunits in mouse SNc fractions treated with Tat-JBD. Sample proteins from SNc fractions were immunoprecipitated (IP) with anti-JIP-1 or anti-JNK3 or JNK1/2 antibodies and then blotted (IB) with anti-JNK3 or JNK1/2 antibodies. Quantitative representation of JIP-1 interactions JNK3 or JIP-1 interaction with JNK1/2. Data are expressed as the mean \pm s.d. and as folds vs ${ }^{\mathrm{a}} P<0.05$ vs saline; ${ }^{\mathrm{b}} P<0.05$ vs MPTP groups ( $n=6$ mice). 
Fluorescence can be observed in SNc of mice subjected cerebral ventricular injection of Tat-JBD-dansyl and Tat-JBD-4Adansyl, whereas the same region showed only a background signal in the mice treated with saline (Figure $1 \mathrm{a}$ and $\mathrm{b}$ ). To elucidate the effects of Tat-JBD on the activation of JNKs, JNK1/2/3 phosphorylations were investigated in MPTPlesioned animals. As indicated in Figure 1c- $\mathrm{f}$, the results of western blotting showed that the phosphorylation and total level of JNKs especially JNK3 were significantly increased after MPTP injection. However, as shown in Figures $1 \mathrm{c}-\mathrm{f}$, the treatment of Tat-JBD remarkably inhibited the phosphorylation of JNK3 as well as JNK1 and 2. The same dose of Tat-JBD-4A did not have the same effect. The protein levels of JNKs were not affected by either Tat-JBD or Tat-JBD-4A treatment.

\section{Tat-JBD Perturbs the Assembly of JIP-1-JNK Complex}

Owing to the poor solubility of expressed full-length JNK3 (data not shown), we expressed the truncated JNK3 $\alpha 1$, which encodes amino acid residues Ser40-Gln422 of JNK3 as described in Xie et al. ${ }^{21}$ Their result already has proved that JNK3 protein lacking the N-terminal 39 residues displayed the similar kinase activity to the JNK3 protein in vitro. Purified His-JNK3 $\alpha 1$ was incubated with control peptide and Tat-JBD. The result of GST-JIP1 (127-282) pull-down assay indicated that JBD peptide could suppress the interaction between JNK3 and JIP-1 in vitro (Figure 2a). To detect whether Tat-JBD could inhibit JNK2 interaction with JIP-1 either, we expressed the full length of JNK2. Purified His-JNK2 was incubated with control peptide and Tat-JBD, respectively. The result of GST-JIP1 (127-282) pull-down assay indicated that JBD peptide could also suppress the interaction between JNK2 and JIP-1 in vitro (Figure 2b).

We next investigated whether Tat-JBD could perturb the assembly of JIP-1-JNK complexes by examining its effects on the co-immunoprecipitation of JIP-1 with JNK in vivo. The cytosolic protein fraction of mice $\mathrm{SNc}$ tissue were from animal models treated with either Tat-JBD or control peptide (Tat-JBD-4A). Results from co-immunoprecipitation indicated that control peptide lacking an intact JNK-binding motif could not suppress the interaction of JNK3 or JNK1/2 with JIP-1, whereas the same dose of Tat-JBD could noticeably suppress their interaction (Figure $2 \mathrm{c}$ and $\mathrm{d}$ ).

\section{Tat-JBD Modulates MPTP-Induced c-Jun Phosphorylation and Fas L Expression}

To elucidate the effects of Tat-JBD on the activation and expression of c-Jun, the nuclear substrate of JNKs, c-Jun phosphorylation was detected in MPTP-lesioned animals. As indicated in Figure $3 \mathrm{a}$ and $\mathrm{b}$, results of western blotting revealed that the phosphorylation and total amount of c-Jun
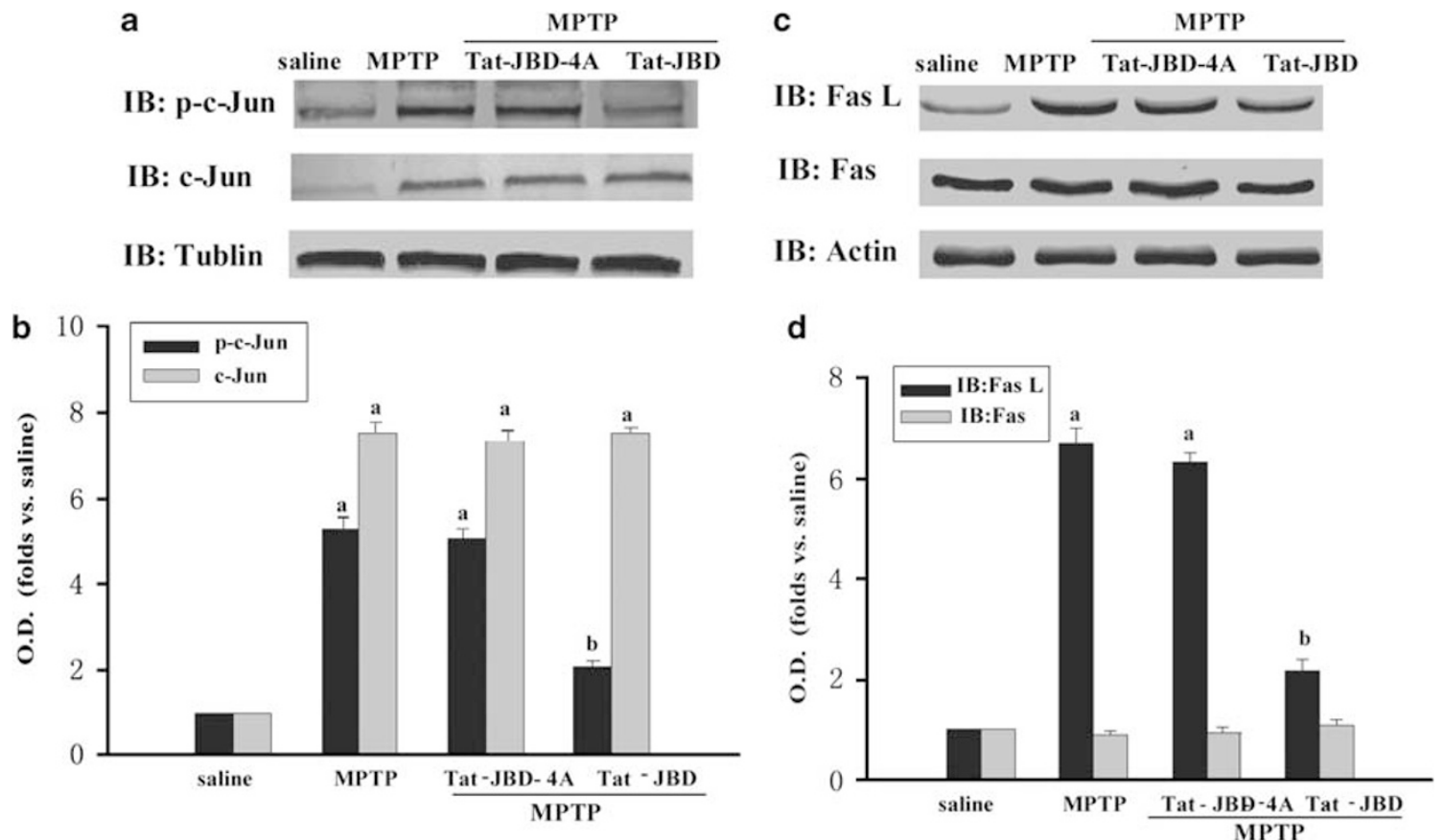

Figure 3 Tat-JBD inhibited the phosphorylation of c-Jun and diminished the increased level of Fas L protein in SNc regions. (a) Effects of Tat peptides on MPTP-induced activation and expression of c-Jun in SNc. Western blot probed with antibodies to phosphorylated c-Jun (p-c-Jun, Ser63/73) and c-Jun. (b) Bands corresponding to $p$-c-Jun and c-Jun were scanned and the intensities were represented as folds vs saline groups. (c) Effects of Tat peptides on the increases of expression of Fas $L$ and Fas induced by MPTP in SNc. Western blot probed with antibodies to Fas $L$ and Fas. (d) Bands corresponding to Fas $L$ and Fas were scanned and the intensities were represented as folds vs saline groups. Data are expressed as mean \pm s.d. $(n=6)$. ${ }^{a} P<0.05$ vs saline; ${ }^{b} P<0.05$ vs MPTP groups ( $n=6$ mice). 
were tremendously increased only in SNc after MPTP injection. Similarly, as shown in Figure $3 \mathrm{a}$ and b p-c-Jun was significantly inhibited only in SNc when MPTP-lesioned animals were treated with Tat-JBD through cerebral ventricle infusion for 5 consecutive days, whereas the same dose of Tat-JBD-4A did not have the same effect. The protein levels of c-Jun were not affected by Tat-JBD or Tat-JBD-4A treatment.

Tat-JBD diminishes the increased expression of Fas L. As indicated in Figure $3 \mathrm{c}$ and $\mathrm{d}$, the expression of Fas $\mathrm{L}$ was significantly increased after MPTP infusion, but the expression of Fas was not apparently increased. Moreover, our results revealed that the increased expression of Fas $\mathrm{L}$ was noticeably suppressed by infusion of the peptide Tat-JBD. The same dose of control peptide Tat-JBD-4A did not affect the increase on the expression of Fas L. The protein level of Fas was not affected by the Tat-JBD and control peptide.

\section{Tat-JBD Inhibits the Phosphorylation of $\mathrm{Bcl}-2$ and the Release of Bax from Bcl-2/Bax Dimmers}

Our previous study indicated that K252a (the inhibitor of JNK upstream) rescued 6-OHDA-induced dopaminergic neuronal death in $\mathrm{SNc}$ via suppressing the phosphorylation of Bcl-2. ${ }^{21}$ Consistent with that result, MPTP lesion can also increase the level of phosphorylated $\mathrm{Bcl}-2$ and decrease the interaction of Bcl-2 with Bax. The application of Tat-JBD can inhibit the phosphorylation of $\mathrm{Bcl}-2$ and sequentially suppress the releasing of $\mathrm{Bax}$ from $\mathrm{Bcl}-2 / \mathrm{Bax}$ dimmers (Figure $4 \mathrm{a}$ and $\mathrm{b}$ ).

\section{Tat-JBD Attenuates Bax Translocation and the Release of Cytochrome $c$}

To elucidate the involvement of mitochondria-mediated apoptotic pathway during MPTP lesion and the action of JNK activity on Bax translocation and the release of cyt $c$, level of Bax and cyt $c$ in mitochondria and cytosol was
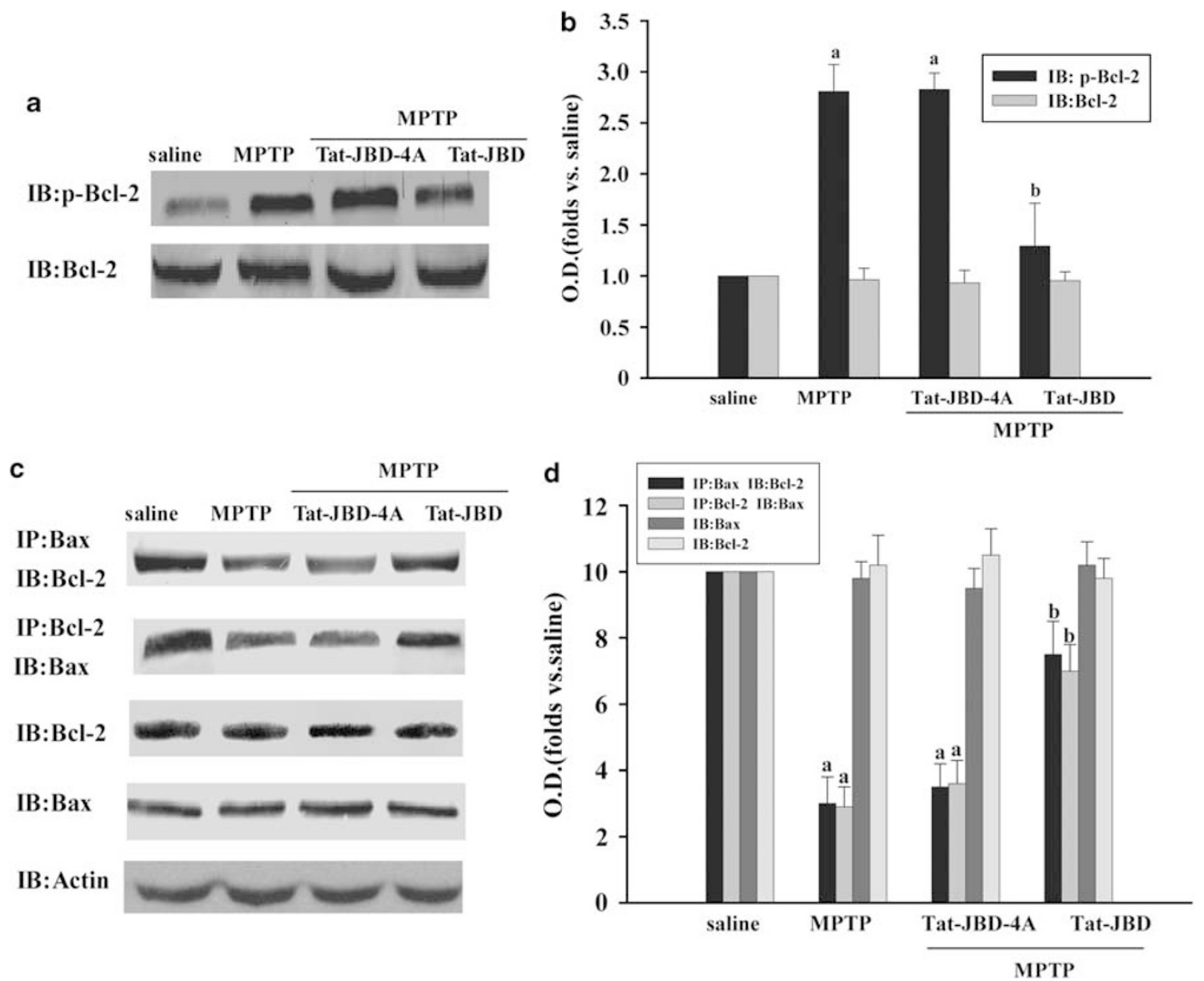

Figure 4 Effects of Tat-JBD on the altered phosphorylation of $\mathrm{BCl}-2$ and interactions of $\mathrm{BCl}-2$ with Bax. (a) Effects of Tat-JBD on the increased phosphorylation of $\mathrm{Bcl}-2$ induced by MPTP in SNc. Western blot probed with antibodies to phosphorylated Bcl-2 ( $\mathrm{p}-\mathrm{Bcl}-2$, Ser87) and Bcl-2. (b) Bands

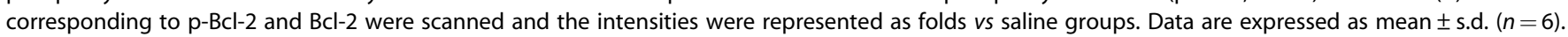
${ }^{\mathrm{a}} \mathrm{P}<0.05$ vs respective saline, ${ }^{\mathrm{b}} \mathrm{P}<0.05$ vs MPTP groups. (c) Co-immunoprecipitation analysis of interactions between Bcl- 2 and Bax. (d) Bands corresponding to $\mathrm{Bax}$ and $\mathrm{Bcl}-2$ were scanned and the intensities were represented as folds $v s$ saline groups. Data are expressed as mean $\pm \mathrm{s}$.d. ${ }^{\mathrm{a}} P<0.05$ vs respective saline, ${ }^{\mathrm{b}} P<0.05$ vs MPTP groups ( $n=6$ mice). 
examined by western blotting. We first determined whether Bax translocates from cytosol to mitochondria after lesion. Using western blotting analysis on different subcellular fractions, we found that the level of Bax was significantly increased in the mitochondria, but not markedly decreased in cytosol (Figure $5 \mathrm{a}$ and $\mathrm{b}$ ). This can be explained by the fact that the overwhelming amount of Bax was located in cytosol, thus partial translocated Bax did not noticeably affect the total protein level of Bax in cytosol. Moreover, we examined whether the inhibition of JNKs by Tat-JBD contributes to attenuating Bax translocation. The inhibitory effect of TatJBD on Bax translocation in the mitochondrial fraction reached a statistical difference compared with that of the control peptide Tat-JBD-4A (Figure 5a and b). A significant amount of mitochondrial cyt $c$ was detected in the saline controls. This portion of cyt $c$ was decreased after MPTP treatment, corresponding to a marked increase in the cytosolic fraction (Figure $5 \mathrm{c}$ and d). The inhibitory effect of Tat-JBD on the release of cyt $c$ in the cytosol fraction reached a statistical difference compared with the control peptide Tat-JBD-4A (Figure $5 \mathrm{c}$ and d). To elucidate whether other mitochondrial proteins were released from mitochondria, we determined the cyt $c$ oxidase level in the cytosolic and mitochondrial fraction using cyt $c$ oxidase subunit IV antibody. The cyt $c$ oxidase subunit IV was detected only in the mitochondrial fraction but not in the cytosolic fraction in saline, MPTP lesion or application of peptide groups (Figure $5 \mathrm{a}-\mathrm{d})$. These results suggested that cyt $c$ oxidase was not coreleased with cyt $c$ from mitochondria.

\section{Tat-JBD Decreases the Activation of Caspase3}

Caspase 3 is one of the key executioners in the apoptotic pathway and is a cytosolic protein as an inactive $32 \mathrm{kDa}$ proenzyme. It is activated by proteolytic cleavage into the $20 \mathrm{kDa}$ (p20) and $11 \mathrm{kDa}$ (p11) active subunits. During apoptosis, caspase 3 cleaves the substrate $116 \mathrm{kDa}$ poly-ADPribose-polymerase (PARP) into an $85 \mathrm{kDa}$ and a $25 \mathrm{kDa}$ fragment. In this study, we examined the activation of caspase 3 and PARP in MPTP lesion and the inhibition of peptide on caspase 3 activation and hydrolyzation of PARP using western blot analysis. As shown in Figure $6 a$ and $b$, the increase of cleaved caspase 3 and hydrolyzation of PARP were obviously suppressed by the treatment of peptide Tat-JBD. The same dose of control peptide Tat-JBD-4A did not affect the increase of cleaved caspase 3 and hydrolyzation of PARP.
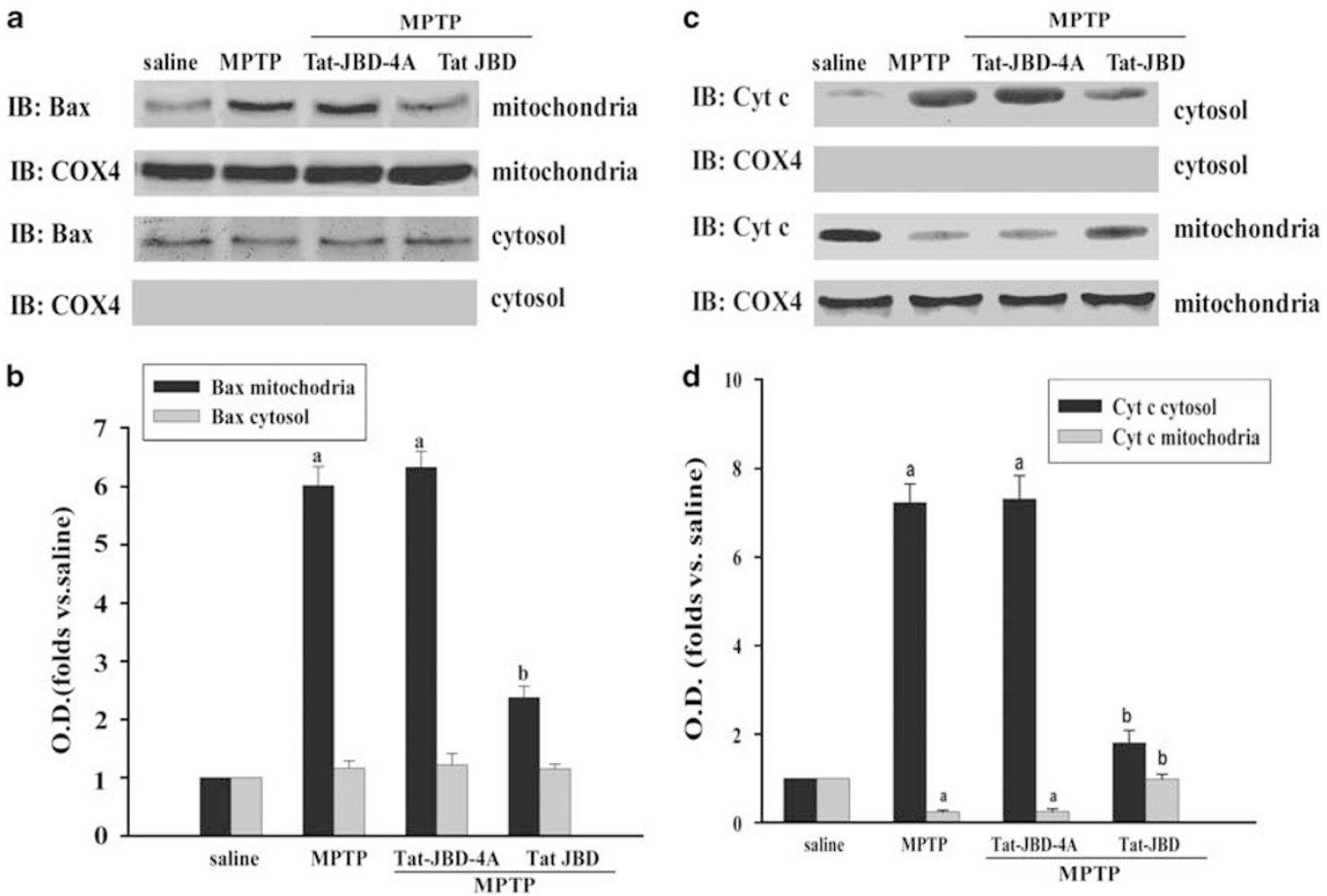

Figure 5 Tat-JBD attenuated the mitochondrial apoptosis-signaling pathway in SNc. (a) Effects of Tat peptides on the level of Bax induced by MPTP in cytosol and mitochondria in SNc. (C) Effects of Tat peptides on the level of cyt c induced by MPTP in cytosol and mitochondria in SNc. COX4 was strongly expressed in the mitochondrial fraction and did not decrease after MPTP lesion, whereas no immunoreactivity was seen in the cytosolic fraction of SNc region in both the saline and MPTP groups. (b and $\mathbf{d}$ ) Bands corresponding to Bax and cyt $c$ were scanned and the intensities were represented as folds vs saline groups. Data are expressed as the mean \pm s.d. and as folds vs respective saline. ${ }^{\mathrm{a}} P<0.05$ vs saline; ${ }^{\mathrm{b}} P<0.05$ vs MPTP groups ( $n=6$ mice). 


\section{Neuroprotective Role of Tat-JBD Against MPTP}

To investigate whether treatment of Tat-JBD would have neuroprotection against MPTP-induced dopaminergic neuronal death, C57BL/6 mice were subjected MPTP lesion. Mice were treated with Tat-JBD or Tat-JBD-4A by cerebral ventricular injection for 5 consecutive days after last MPTP injection.

We first examined the effect of Tat-JBD on tyrosine hydroxylase (TH)-positive neurons in SNc of MPTP animal model. As shown in Figure 7a(A), MPTP-induced marked nigral cell death (Figure $7 \mathrm{a}(\mathrm{B})$ ). However, administration of Tat-JBD clearly rescued the neurodegeneration caused by MPTP (Figure $7 \mathrm{a}(\mathrm{D})$ ). At the same time, as the control, Tat-JBD-4A did not show any protection (Figure $7 \mathrm{a}(\mathrm{C})$ ). The results indicated that Tat-JBD was capable of protecting neurons against MPTP-induced injury. TH immunostaining in the striatum was assessed as an indication of dopaminergic axon. The results revealed that Tat-JBD treatment minimized the decreased densities of dopaminergic axon in the caudateputamen $(\mathrm{CP})$ region of the striatum (Figure $\left.7 \mathrm{a}\left(\mathrm{D}_{1}\right)\right)$, whereas the Tat-JBD-4A did not have such effect (Figure $7 \mathrm{a}\left(\mathrm{C}_{1}\right)$ ).

Mice were perfusion-xed with paraformaldehyde and TUNEL staining was used to examine the apoptosis of dopaminergic neurons in SNc (Figure 7b). A significant number

a

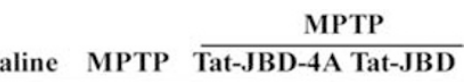

IB: cleaved caspase 3

IB: cleaved PARP

IB: actin

b

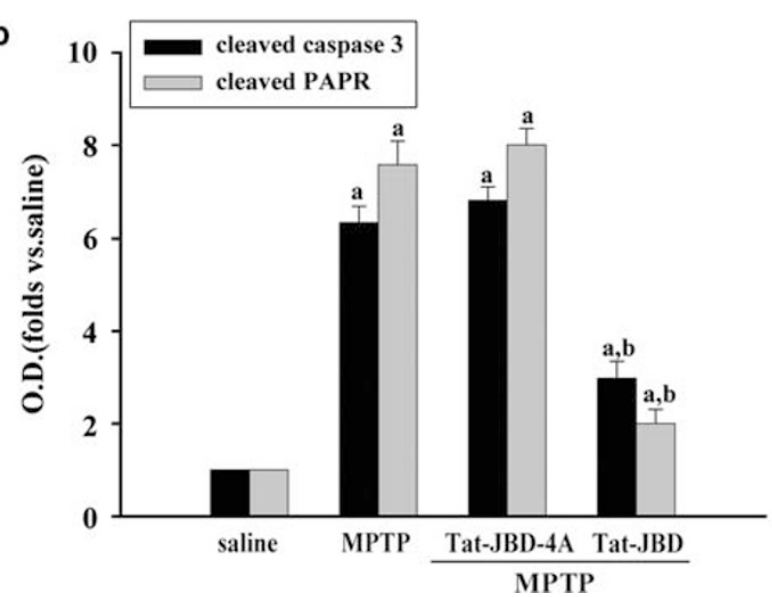

Figure 6 Tat-JBD decreased the activation of caspase-3 in cytosol in SNC regions of MPTP-treated mice. (a) Effects of Tat peptides increased the level of cleaved Caspase 3 and cleaved PARP in cytosol-induced MPTP lesion in SNc. Western blot probed with antibodies to cleaved Caspase3 and cleaved PARP. (b) Bands corresponding to cleaved caspase 3 and cleaved PARP were scanned and the intensities were represented as folds vs saline control. Data are the mean \pm s.d. and were expressed as folds vs respective saline. ${ }^{\mathrm{a}} P<0.05$ vs saline control ${ }^{\mathrm{b}} P<0.05$ vs MPTP injection groups ( $n=6$ mice). of positive cells were observed (Figure $7 b\left(B, B_{2}\right)$ ). Some of them showed characteristic appearances, such as shrunken, condensed nuclei and apoptotic bodies. However, others revealed lightly stained, large and swollen nuclei, as the results showing the administration of Tat-JBD significantly decreased TUNEL-positive cells (Figure $7 \mathrm{~b}\left(\mathrm{D}, \mathrm{D}_{2}\right)$ ). At the same time, we examined the effect of Tat-JBD on TH-positive neurons in SNc of MPTP mouse. The results indicated that Tat-JBD was capable of protecting neurons against MPTPinduced injury.

\section{DISCUSSION}

Various mechanisms have been proposed to account for the neurodegeneration induced by MPTP. Early studies suggested that MPTP-induced neuronal damage in vitro was because of the activation of JNK-signaling pathway. The JNKs, first characterized by their activation following exposure to various forms of cellular stress, are now suggested to have important roles in the regulation of neuronal death including nigral dopaminergic neurons.

There are three isoforms of JNKs, JNK1, JNK2 and JNK3, which has distinct roles. ${ }^{8,29,30}$ JNK1 is primarily responsible for the level of basal JNK activity in the brain, ${ }^{30}$ whereas the activated JNK2 and JNK3 proved to be related to neuronal death in 6-OHDA-treated mice. ${ }^{31}$ As aforementioned, targeted disruption of the Jnk3 gene not only reduced the downstream effector c-Jun phosphorylation, but also remarkably protected mice from brain injury after MPTP lesion. ${ }^{9}$ These studies indicated the functional diversity of JNK isoforms and suggested that the activation of JNKs is a critical factor in PD pathogenesis. The level of phosphorylated JNKs is increased in our MPTP mice also showed the role of activated JNKs in neuronal death in the PD animal model.

A number of studies including ours already showed that the activation of JNK relies on the formation of JNK cascade and is related to neuronal death. ${ }^{32}$ JIP- 1 is believed to interact with MLK3, MKK7 and JNK, help to form the JNK-signaling module and facilitate the activation of JNK signaling. ${ }^{33,34}$ Disrupting the interaction between JIP-1 and any kinase in JNK cascade will inhibit the activation of JNKs effectively. In recent years, more attention has been paid to the effect of the peptides derived from JBD (JIP-1 127-281), which perturbs the assembly of JIP-1-JNK complexes, on the therapy of various diseases. Furthermore, Barr $e t \mathrm{al}^{20}$ found that a shorter peptide corresponding to the sequence 153-163 of JIP-1 also effectively inhibit JNK activity in vivo. It indicated that this region is responsible for the interaction between JIP-1 and JNKs.

On the basis of the above-mentioned findings, we synthesized a new peptide Tat-JBD. The membrane transduction domain of the HIV-1 was fused to the peptide to help the peptide enter the cells easily. Fluorescence examination showed that Tat-JBD could enter the cells effectively and localized at $\mathrm{SNc}$ when it was injected through cerebral ventricular in MPTP mice. 
Both in vitro and in vivo studies show that treatment of the peptide Tat-JBD can inhibit the binding between JIP-1 and JNKs and attenuate the activation of JNKs induced by MPTP lesion. The activation of JNK2 and JNK3 were thought to be responsible for the dopamine neuron death in MPTP mice. In our experiment the phosphorylation level of JNK3 is higher than that of JNK1 and JNK2. Furthermore, it is wellknown that the products of the JNK1 and JNK2 genes are ubiquitously expressed, whereas the expression of JNK3 is restricted predominantly to the brain. ${ }^{8}$ All these indicate that JNK3 may have a more important role than JNK1/2 in MPTP-induced dopaminergic neuronal death.

Nevertheless, the downstream mechanism that accounts for the proapoptotic actions of JNK remains to be investigated in detail. ${ }^{35,36}$ This study showed that treatment of Tat-JBD attenuated the increased phosphorylation of c-Jun induced by MPTP lesion in SNc. Activated JNK phosphor- ylates the transcription factor c-Jun and leads to the increase of AP-1 transcription activity to modulate transcription of a number of genes such as Fas L. ${ }^{37-39}$ Results from our present study suggested that through c-Jun/AP-1-mediated transcriptional regulation, activation of JNKs may enhance the expression of Fas L, which can ultimately contribute to Fas receptor-mediated apoptosis. Taken together, these results suggest that the nuclear signal pathway mediated by JNKs activation is involved in dopaminergic neuronal death induced by MPTP.

Besides the nuclear pathway, JNKs can also promote cell death by regulating the activation of some non-nuclear substrates, such as Bcl-2 family members. ${ }^{38,40}$ Previous studies have also indicated that phosphorylation inactivates $\mathrm{Bcl}-2$, thus promoting apoptosis, possibly by releasing Bax from $\mathrm{Bcl}-2 / \mathrm{Bax}$ dimmers. ${ }^{38,41,42}$ The $\mathrm{Bcl}-2 / \mathrm{Bax}$ heterodimer is the active component for death protection. ${ }^{43,44}$ In response
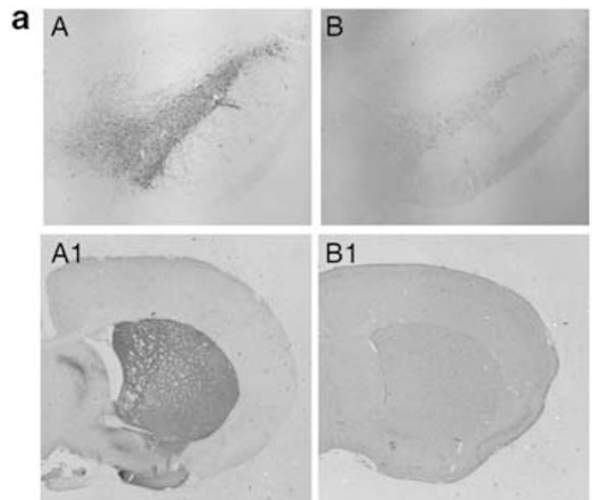

b
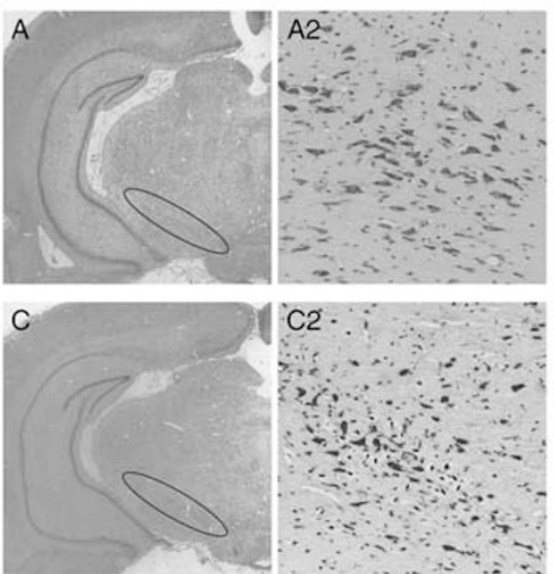
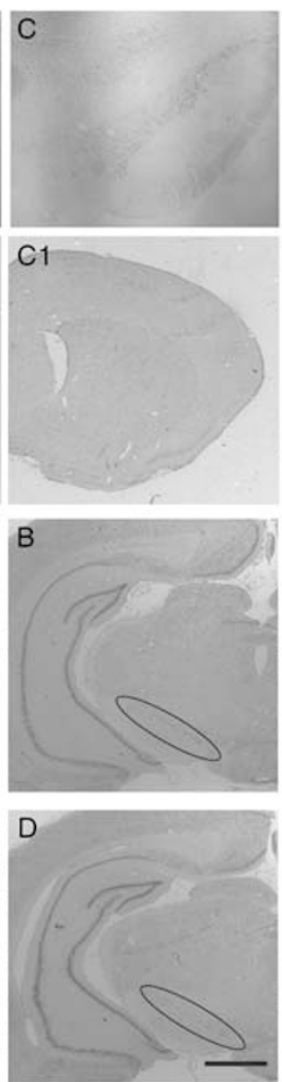
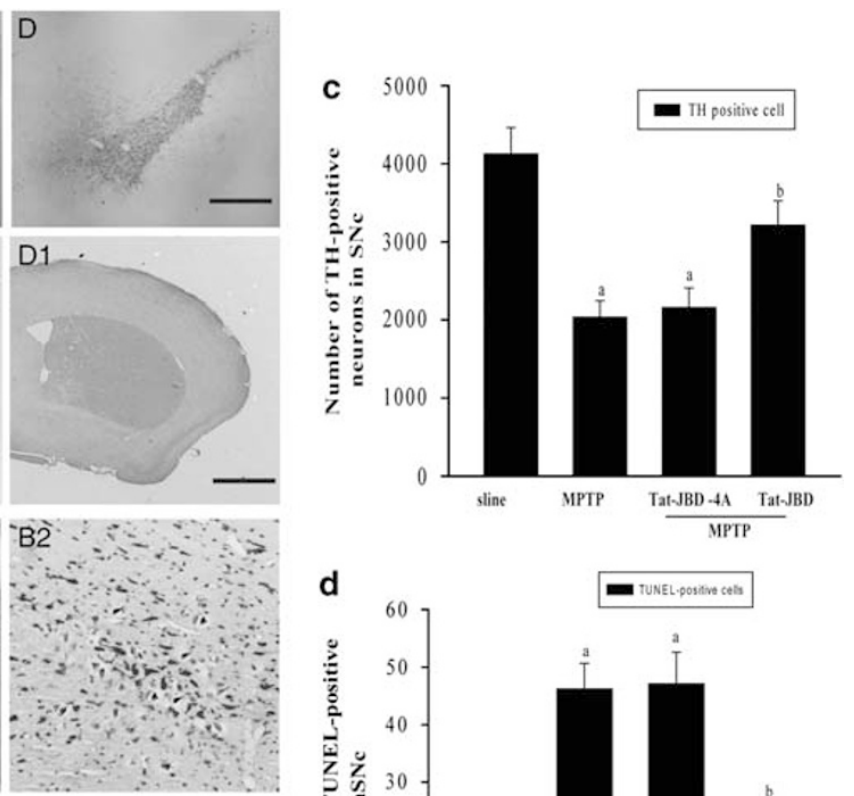

d
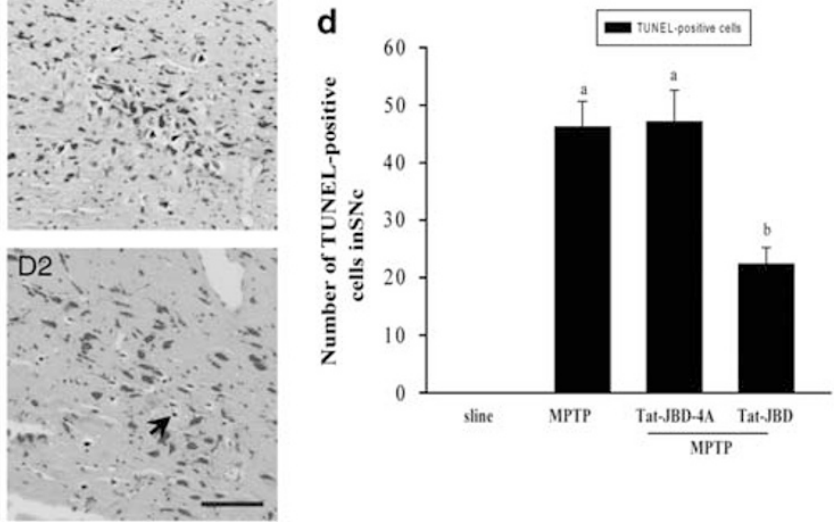

Figure 7 Effects of Tat-JBD on cell death and survival in SNc. (a) Tat-JBD attenuated MPTP-induced DA terminal loss in striatum and dopaminergic neuronal death in the SNc. TH-stained sections of SNc in saline group (a-A), mice subjected MPTP-induced lesion (a-B), administration of the Tat-JBD-4A (a-C) and Tat-JBD (a-D) following MPTP injection. When compared to Tat-JBD treated mice $\left(\mathbf{a}-\mathrm{D}_{\mathbf{1}}\right)$, Tat-JBD-4A-treated mice following MPTP lesion showed marked reduction in TH-positive fibers in striatum $\left(\mathbf{a}-C_{1}\right) .\left(\mathbf{a}-A_{1}, \mathbf{a}-B_{1}\right)$ TH staining in striatum of saline and MPTP-treated mice. Scale bars: $A, B, C, D=200 \mu m ;\left(A_{1}, B_{1}\right.$, $\left.C_{1}, D_{1}\right)=400 \mu \mathrm{m}$. (c) Quantitative analysis of the protective effects of Tat-JBD against MPTP-induced mice model of nigrostriatal damage. ${ }^{a} P<0.05$ vs saline control ${ }^{b} P<0.05$ vs MPTP injection groups. (b) Representative SNc photomicrographs of TUNEL staining counterstained with methyl green were shown. Mice were subjected to saline (b-A, b- $\left.A_{2}\right)$ and MPTP (b-B, $\left.\mathbf{b}-B_{2}\right)$, and mice subjected to MPTP with administration of $100 \mu \mathrm{g} / 4 \mu$ l of Tat-JBD-4A (b-C, $\left.\mathbf{b}-\mathrm{C}_{2}\right)$ or $100 \mu \mathrm{g} / 4 \mu \mathrm{l}$ of Tat-JBD (b-D, $\mathbf{b}-\mathrm{D}_{2}$ ) for 5 days after i.p. MPTP. Some cells had shrunken, darkly stained nuclei and apoptotic bodies (arrowheads). Others had lightly stained, large and swollen nuclei. Boxed areas in left column are shown at higher magnification in right column. $A, B, C, D: \times 40 ; A_{2}, B_{2}, C_{2}, D_{2}: \times 400$. Scale bar in $\mathrm{D}=200 \mu \mathrm{m}$; scale bar in $\mathrm{D}_{2}=10 \mu \mathrm{m}$. (d) Quantitative analysis of the protective effects of Tat-JBD against MPTP-induced mice model of nigrostriatal damage. ${ }^{a} P<0.05$ vs saline control; ${ }^{b} P<0.05$ vs MPTP-injection groups. 
to apoptotic stimulation, Bax can be released from Bcl-2/Bax dimmers and act as the channels for either ions or proteins. $^{38,45}$ This proapoptotic protein Bax forms pores in the outer mitochondrial membrane which helps in the releasing of cyt $c{ }^{46}$ As Tat-JBD could inhibit the activation of JNK, we showed that treatment of the peptides inhibited the phosphorylation of $\mathrm{Bcl}-2$ proteins, increased the interaction of Bcl-2 with Bax, prevented Bax translocation to mitochondria, and attenuated the release of cyt $c$ and caspase-3 activation. $^{14,19,39,42}$ This suggests that the mitochondriadependent apoptosis pathway mediated by JNKs activation is also involved in dopaminergic neuronal apoptosis induced by MPTP-injury.

As the treatment of the peptides could inhibit the activation of JNKs induced by MPTP lesion through blocking the interaction between JNKs and JIP-1, we inferred that application of the peptides would also restore dopaminergic terminals as well as SNc cell bodies from degeneration. Our present study proved that the Tat-JBD peptide was capable of preventing dopaminergic neurons from degeneration following MPTP insult. Moreover, TUNEL results provided strong evidence that the peptide could protect the dopaminergic neurons from apoptosis. As significant neuroprotection was achieved by Tat-JBD at the onset of PD, Tat-JBD shows great clinical relevancy and provides a novel way for the treatment of PD.

\section{ACKNOWLEDGEMENTS}

This work was sponsored by grants from the National Program of Basic Research of China (2006CB500706, 2007CB947900), National Natural Science Fundation of China (30872729, 30770732), Shanghai Pujiang Program (08PJ1407900), Shanghai Key Discipline Program (S30202) Major Program of Science and Technology Commission of Shanghai (07DJ14005) and Program for Outstanding Medical Academic Leader (LJ 06003).

\section{DISCLOSURE/CONFLICT OF INTEREST}

The authors declare no conflict of interest.

1. Forno LS. Neuropathology of Parkinson's disease. J Neuropathol Exp Neurol 1996;55:259-272.

2. Boulet S, Mounayar S, Poupard A, et al. Behavioral recovery in MPTPtreated monkeys: neurochemical mechanisms studied by intrastriatal microdialysis. J Neurosci 2008;28:9575-9584.

3. Redmond Jr DE, Bjugstad KB, Teng YD, et al. Behavioral improvement in a primate Parkinson's model is associated with multiple homeostatic effects of human neural stem cells. Proc Natl Acad Sci USA 2007;104:12175-12180.

4. Yujiri T, Sather S, Fanger GR, et al. Role of MEKK1 in cell survival and activation of JNK and ERK pathways defined by targeted gene disruption. Science 1998;282:1911-1914.

5. Huang C, Rajfur Z, Borchers C, et al. JNK phosphorylates paxillin and regulates cell migration. Nature 2003;424:219-223.

6. Becker EB, Bonni A. Pin1 mediates neural-specific activation of the mitochondrial apoptotic machinery. Neuron 2006;49:655-662.

7. Xiao D, Powolny AA, Singh SV. Benzyl isothiocyanate targets mitochondrial respiratory chain to trigger ros-dependent apoptosis in human breast cancer cells. J Biol Chem 2008;283:30151-30163.

8. Turjanski AG, Vaque JP, Gutkind JS. MAP kinases and the control of nuclear events. Oncogene 2007;26:3240-3253.

9. Kuan CY, Whitmarsh AJ, Yang DD, et al. A critical role of neural-specific JNK3 for ischemic apoptosis. Proc Natl Acad Sci USA 2003;100: 15184-15189.
10. Hunot S, Vila M, Teismann P, et al. JNK-mediated induction of cyclooxygenase 2 is required for neurodegeneration in a mouse model of Parkinson's disease. Proc Natl Acad Sci USA 2004;101:665-670.

11. Brecht $S$, Kirchhof R, Chromik A, et al. Specific pathophysiological functions of JNK isoforms in the brain. Eur J Neurosci 2005;21:363-377.

12. Kim JW, Kim MJ, Kim KJ, et al. Notch interferes with the scaffold function of JNK-interacting protein 1 to inhibit the JNK signaling pathway. Proc Natl Acad Sci USA 2005;102:14308-14313.

13. Nihalani D, Wong HN, Holzman LB. Recruitment of JNK to JIP1 and JNK-dependent JIP1 phosphorylation regulates JNK module dynamics and activation. J Biol Chem 2003;278:28694-28702.

14. Santos $C R$, Blanco $S$, Sevilla $A$, et al. Vaccinia virus B1R kinase interacts with JIP1 and modulates c-Jun-dependent signaling. J Virol 2006;80:7667-7675.

15. Eilers A, Whitfield J, Shah B, et al. Direct inhibition of c-Jun N-terminal kinase in sympathetic neurones prevents c-jun promoter activation and NGF withdrawal-induced death. J Neurochem 2001;76:1439-1454.

16. Nikulina MA, Sandhu N, Shamim Z, et al. The JNK binding domain of islet-brain 1 inhibits IL-1 induced JNK activity and apoptosis but not the transcription of key proapoptotic or protective genes in insulinsecreting cell lines. Cytokine 2003;24:13-24.

17. Eilers $\mathrm{A}$, Whitfield J, Shah B, et al. Direct inhibition of c-Jun N-terminal kinase in sympathetic neurones prevents $c$-jun promoter activation and NGF withdrawal-induced death. J Neurochem 2001;76:1439-1454.

18. Bienemann AS, Lee $Y B$, Howarth J, et al. Hsp70 suppresses apoptosis in sympathetic neurones by preventing the activation of c-Jun. J Neurochem 2008;104:271-278.

19. Harding TC, Xue L, Bienemann A, et al. Inhibition of JNK by overexpression of the JNK binding domain of JIP-1 prevents apoptosis in sympathetic neurons. J Biol Chem 2001;276:4531-4534.

20. Barr RK, Kendrick TS, Bogoyevitch MA. Identification of the critical features of a small peptide inhibitor of JNK activity. J Biol Chem 2002;277:10987-10997.

21. Xie X, Gu Y, Fox T, et al. Crystal structure of JNK3: a kinase implicated in neuronal apoptosis. Structure 1998;6:983-991.

22. Pan J, Wang G, Yang HQ, et al. K252a prevents nigral dopaminergic cell death induced by 6-hydroxydopamine through inhibition of both mixed-lineage kinase 3/c-Jun NH2-terminal kinase 3 (JNK3) and apoptosis-inducing kinase 1/JNK3 signaling pathways. Mol Pharmacol 2007;72:1607-1618.

23. Pan J, Zhao YX, Wang ZQ, et al. Expression of FasL and its interaction with Fas are mediated by c-Jun N-terminal kinase (JNK) pathway in 6-OHDA-induced rat model of Parkinson disease. Neurosci Lett 2007;428:82-87.

24. Pan J, Zhang QG, Zhang GY. The neuroprotective effects of K252a through inhibiting MLK3/MKK7/JNK3 signaling pathway on ischemic brain injury in rat hippocampal CA1 region. Neuroscience 2005:131:147-159.

25. Pan J, Pei DS, Yin XH, et al. Involvement of oxidative stress in the rapid Akt1 regulating a JNK scaffold during ischemia in rat hippocampus. Neurosci Lett 2006;392:47-51.

26. Furuya $T$, Hayakawa $H$, Yamada $M$, et al. Caspase- 11 mediates inflammatory dopaminergic cell death in the 1-methyl-4-phenyl1,2,3,6-tetrahydropyridine mouse model of Parkinson's disease. J Neurosci 2004;24:1865-1872.

27. Mandir AS, Przedborski S, Jackson-Lewis V, et al. Poly(ADP-ribose) polymerase activation mediates 1-methyl-4-phenyl-1, 2,3,6tetrahydropyridine (MPTP)-induced parkinsonism. Proc Natl Acad Sci USA 1999;96:5774-5779.

28. Cao $X Q$, Arai $H$, Ren YR, et al. Recombinant human granulocyte colonystimulating factor protects against MPTP-induced dopaminergic cell death in mice by altering $\mathrm{Bcl}-2 / \mathrm{Bax}$ expression levels. J Neurochem 2006;99:861-867.

29. Sury MD, Agarinis C, Widmer HR, et al. JNK is activated but does not mediate hippocampal neuronal apoptosis in experimental neonatal pneumococcal meningitis. Neurobiol Dis 2008;32:142-150.

30. Bogoyevitch MA. The isoform-specific functions of the c-Jun $\mathrm{N}$-terminal Kinases (JNKs): differences revealed by gene targeting. Bioessays 2006;28:923-934.

31. Ries V, Silva RM, Oo TF, et al. JNK2 and JNK3 combined are essential for apoptosis in dopamine neurons of the substantia nigra, but are not required for axon degeneration. J Neurochem 2008;107: $1578-1588$. 
32. Zhang QG, Wang R, Khan M, et al. Role of Dickkopf-1, an antagonist of the Wnt/beta-catenin signaling pathway, in estrogen-induced neuroprotection and attenuation of tau phosphorylation. J Neurosci 2008;28:8430-8441.

33. Mooney LM, Whitmarsh AJ. Docking interactions in the c-Jun N-terminal kinase pathway. J Biol Chem 2004;279:11843-11852.

34. Willoughby EA, Perkins GR, Collins MK, et al. The JNK-interacting protein-1 scaffold protein targets MAPK phosphatase-7 to dephosphorylate JNK. J Biol Chem 2003;278:10731-10736.

35. Jacobs WB, Govoni G, Ho D, et al. p63 is an essential proapoptotic protein during neural development. Neuron 2005;48:743-756.

36. Xu Z, Sproul A, Wang W, et al. Siah1 interacts with the scaffold protein POSH to promote JNK activation and apoptosis. J Biol Chem 2006;281:303-312.

37. Matsumoto N, Imamura R, Suda T. Caspase-8- and JNK-dependent AP1 activation is required for Fas ligand-induced IL-8 production. FEBS $J$ 2007;274:2376-2384.

38. Pei DS, Wang XT, Liu $Y$, et al. Neuroprotection against ischaemic brain injury by a GluR6-9c peptide containing the TAT protein transduction sequence. Brain 2006;129:465-479.

39. Pei DS, Song YJ, Yu HM, et al. Exogenous nitric oxide negatively regulates $\mathrm{c}$-Jun $\mathrm{N}$-terminal kinase activation via inhibiting endogenous NO-induced S-nitrosylation during cerebral ischemia and reperfusion in rat hippocampus. J Neurochem 2008;106:1952-1963.

40. Fontanini A, Foti $\mathrm{C}$, Potu $\mathrm{H}$, et al. The isopeptidase inhibitor $\mathrm{G} 5$ triggers a caspase-independent necrotic death in cells resistant to apoptosis: a comparative study with the proteasome inhibitor bortezomib. J Biol Chem 2009;284:8369-8381.

41. Biswas SC, Shi Y, Sproul A, et al. Pro-apoptotic Bim induction in response to nerve growth factor deprivation requires simultaneous activation of three different death signaling pathways. J Biol Chem 2007;282:29368-29374.

42. Liu XM, Pei DS, Guan QH, et al. Neuroprotection of Tat-GluR6-9c against neuronal death induced by kainate in rat hippocampus via nuclear and non-nuclear pathways. J Biol Chem 2006;281: 17432-17445.

43. Zhang Z, Lapolla SM, Annis MG, et al. Bcl-2 homodimerization involves two distinct binding surfaces, a topographic arrangement that provides an effective mechanism for $\mathrm{Bcl}-2$ to capture activated Bax. J Biol Chem 2004;279:43920-43928.

44. Rezende AC, Vieira AS, Rogerio F, et al. Effects of systemic administration of ciliary neurotrophic factor on $\mathrm{Bax}$ and $\mathrm{BCl}-2$ proteins in the lumbar spinal cord of neonatal rats after sciatic nerve transection. Braz J Med Biol Res 2008;41:1024-1028.

45. Patel JR, Brewer GJ. Age-related differences in NFkappaB translocation and $\mathrm{BCl}-2 / \mathrm{Bax}$ ratio caused by TNFalpha and Abeta42 promote survival in middle-age neurons and death in old neurons. Exp Neurol 2008;213:93-100.

46. Mohan J, Gandhi AA, Bhavya BC, et al. Caspase-2 triggers Bax-Bak-dependent and -independent cell death in colon cancer cells treated with resveratrol. J Biol Chem 2006;281: 17599-17611. 